\title{
AN APPLICATION OF THE IDEA MODEL IN THE ASSESSMENT OF CONTAINER TERMINALS EFFICIENCY WITH AN INTANGIBLE INPUT
}

\author{
Carlos Frederico Alves ${ }^{1 *}$ and Fernando Seabra ${ }^{2}$
}

Received October 24, 2020 / Accepted February 27, 2021

\begin{abstract}
The assessment of port efficiency through Data Envelopment Analysis (DEA) is a valuable tool for ensuring accurate investment decisions in this capital-intensive industry. This study analyses the application of DEA on container ports. It assesses the efficiency of Brazilian container ports by proposing the inclusion of an intangible input related to the management practices of the terminals. In order to verify the effects of this input inclusion, the efficiency of 13 terminals is evaluated through the application of an IDEA-CRS model, which enables an appropriate handling of qualitative variables, with an orientation to the maximization of a single output, the annual container throughput, and inputs related to infrastructure, superstructure, and management unchanged. Model findings stress out the relevance of this intangible variable and the result that only three terminals are assessed as efficient, wherein the ones with the most robust management structure were not necessarily the most efficient.
\end{abstract}

Keywords: DEA, intangible input, container terminals management.

\section{INTRODUCTION}

Port activity is of fundamental importance for Brazilian international trade, and efficiently planning investments in this sector is essential for developing it in a national perspective, maximizing results without wasting resources. Container throughput in Brazilian ports, which accounted for approximately 9.3 million TEUs in 2017, according to the National Agency for Waterway Transportation yearly database (ANTAQ, 2018), is expected to reach approximately 20 million TEUs in 2060, as stated in the Brazilian National Ports and Logistics Master Plan (PNLP) released in 2017 , revealing a huge investment need and potential in the upcoming years.

At the international level, although throughput volumes have increased continuously over the last decade, there has been a decrease in the pace of growth since 2014 (UNCTAD, 2018). While analysts predict the maintenance of low growth rates in container handling in the short to medium

\footnotetext{
*Corresponding author

${ }^{1}$ Universidade Federal de Santa Catarina (UFSC), CTC/ECV/PPGTG, Secretaria Bloco C, $2^{\circ}$ Andar, Sala 202C, 88040970 Florianópolis, SC, Brazil - E-mail: alvescarlosf@ gmail.com - https://orcid.org/0000-0003-3525-6092

${ }^{2}$ Universidade Federal de Santa Catarina (UFSC), CTC/ECV/PPGTG, Secretaria Bloco C, $2^{\circ}$ Andar, Sala 202C, 88040970 Florianópolis, SC, Brazil - E-mail: f.seabra@ufsc.br - https://orcid.org/0000-0003-0268-6053
} 
term, some market trends to enhance competition advantage and economies of scale have been observed such as the growth of the dimensions of container ships in the shipbuilding order book as well as mergers among the biggest players in the market, both between shipowners and the terminals - result in pressure on the operational performance of container terminals (LLOYD'S LIST, 2017).

According to Notteboom (2012), the container handling industry has a capital-intensive nature, and the adjustments of terminals to market demands require substantial investments. Therefore, terminal performance optimization, best practices benchmarking and implementation, and competitive environment establishment are necessary measures to be developed, given the limitation of financial resources availability. In other words, it is necessary to maximize terminals efficiency.

Cullinane and Wang (2010) point out that it is recurrent in empirical studies finding evidence of a critical dependence between the competitiveness of port facilities and their level of efficiency. In order to estimate enterprises' efficiency levels, several methods are available in the literature, among which those related to the production frontier have considerably spread recently.

Given the economic importance of container terminals and the increase in competitiveness between them, the evaluation of efficiency is an essential element for terminals management, port operators, shipping lines, and port planning at the regional and national level (CULLINANE; WANG, 2010). According to Lu et al. (2015), excessive and inappropriate investment induces inefficiency and waste of resources, so that efficiency optimization through the rational use of the available infrastructure and superstructure is the viable solution to maintain a competitive terminal.

It should be added that, normally, only tangible inputs and outputs are used as the facilities infrastructure and superstructure characteristics for performance evaluation, especially in the port sector, not considering intangible inputs such as managerial aspects or knowledge assets. There are some studies however that highlight the importance of intangible inputs in the quality of services and competitiveness of port facilities (PAK et al., 2015), or even in the financial results of companies in different sectors (BONTEMPI; MAIRESSE, 2015).

Considering the exposed scenario, this study aims to contribute for broadening the container port efficiency assessment methodology spectrum, by proposing the inclusion of a managerial related intangible input in the Data Envelopment Analysis (DEA) in the evaluation. For this purpose, the efficiency of 13 Brazilian container terminals is assessed through the application of Imprecise Data Envelopment Analysis (IDEA) model using, among other variables, an intangible input related to management practices of the terminals.

The sequence of this study is organized as follows: in section 2 different approaches for assessing efficiency in the port industry are presented and compared; in section 3 the steps for modelling the solution, collecting the data and solving the model are discussed; in section 4 the results of the model are analyzed; and in section 5 some final considerations are made as well as some suggestions for further researches are listed. 


\section{PORT EFFICIENCY: DEFINITIONS AND METHODS}

When efficiency issues are addressed in the business context, it often concerns the success in producing as much output as possible, given a set of inputs (FARRELL, 1957). To measure this efficiency, according to González \& Trujillo (2009), it is necessary to compare the observed values of an entity's inputs and outputs with the optimal values resulting from the relationship between these same variables of a group of similar entities.

These optimal values, as explained by Suárez-Alemán et al. (2016), configure a production frontier. This function encompasses the set of maximum output values, given different input values, or the minimum value of a set of inputs, given different output values, as introduced in a pioneer study led by Farrell (1957). Thus, an entity's efficiency can be measured by the distance between the observed position of its inputs and outputs rates and the production frontier, which represents the best practices identified.

In the last three decades, according to González \& Trujillo (2009), two major approaches have been developed to estimate the production frontier and measure efficiency: the econometric approach and the mathematical programming, whose most frequently adopted models are, respectively, the Stochastic Frontier Analysis (SFA) and DEA. These two methods are explained and compared in the respective sections in the sequence of this section.

\subsection{Stochastic Frontier Analysis (SFA)}

The Stochastic Frontier Analysis (SFA) method is an econometric approach developed by Aigner et al. (1977) to estimate efficiency by analyzing the production frontier, introducing the specification of the stochastic error term, in order to consider possible statistical noise in the model. The efficiency of a decision-making unit (DMU) is represented by an index between 0 and 1 , where 1 indicates that a unit is efficient, derived by the relationship between the observed output and the maximum feasible output given the available inputs, considering the deviation from the optimum frontier due to the stochastic error term.

The main difference between DEA and SFA is that the first is based on a non-parametric and deterministic approach, while the second is a parametric method and, as its name suggests, stochastic. Stochastic approaches allow inefficiency to be distinguished from statistical noise, while in deterministic models, deviations from the efficient frontier are considered an exclusive result of inefficiency.

On the other hand, the parametric characteristic of SFA implies the need to specify a model functional form. If it is subjected to any inadequacy, this will be taken by mistake as inefficiency. Nonparametric models are less sensitive to this type of error since they do not require this kind of specification on the data (GONZÁLEZ; TRUJILLO, 2009). 


\subsection{Data Envelopment Analysis (DEA)}

The DEA method is a deterministic, nonparametric approach based on linear programming, which estimates the relative efficiency of selected DMUs given a set of specific inputs. According to Lu et al. (2015), this efficiency estimate is achieved through the construction of a single "virtual" output for a single "virtual" input without the need to define a production function.

While the method implies the definition of the efficiency frontier for a homogeneous group of DMUs, the application of DEA also makes it possible to compare the inputs used and outputs obtained by each of these units, and sets the efficient benchmark for each inefficient DMU. According to Vieira et al. (2014), this comparative characteristic allows the foundation of action plans applied to inefficient DMUs.

Since the first proposition of DEA, several alternative models were developed to handle specific characteristics of the case in study or the data available. Some of these models and the justification for choosing IDEA model in this study are presented in the following subsections, and the orientation alternatives of DEA, its target and benchmark characteristics and a further comparison with other methods.

\subsubsection{DEA models}

The DEA method was initially proposed by Charnes et al. (1978), from which different models were derived. This original model, known as DEA-CCR (an acronym for the authors Charnes, Copper \& Rhodes), or DEA-CRS (standing for Constant Returns to Scale), is represented by a linear frontier and assumes that variations in inputs imply proportional variations in outputs.

Another model frequently applied in studies related to efficiency assessment in the port sector is DEA-BCC, named after its authors (BANKER; CHARNES; COOPER, 1984), and also known as DEA-VRS (an acronym for Variable Returns to Scale). Unlike DEA-CCR, this model admits that variations in inputs incur variable returns on outputs, as the name suggests, which can be increasing, constant or decreasing variations.

DEA-BCC considers that DMUs that operate with reduced input may be subjected to increasing returns to scale as more inputs are added and vice versa. This model typically results in a relatively large number of efficient units, as stated by Souza et al. (2007), and is intended to compensate for the existence of imperfect competition related to the availability of inputs and to mitigate the heterogeneity of the units evaluated.

Both DEA-CCR and DEA-BCC models are formulated to fit exclusively quantitative variables in order to estimate the relative efficiencies of observed DMUs. However, as Shen et al. (2011) explained, many real situations cannot be comprehensively modeled solely with quantitative variables, while qualitative elements cannot always be quantified in a proper manner to be dealt with other quantitative data. In such cases, these basic models of the DEA cannot provide a satisfactory solution for the problem assessed. 
Cooper et al. (1999) developed an alternative model of the DEA method, so-called IDEA, to better handle the data in these cases. This model accommodates the use of qualitative variables, usually on a hierarchical ordinal scale or a subjective judgment scale, such as the Likert scale, treating them separately from quantitative variables. This particular treatment is necessary since it cannot be assumed, for example, that the position two in a Likert scale is equivalent to twice or even the half of position one value, and it can only be stated that the first is preferable or not to the second (SHEN et al., 2011).

Some publications such as Zhu (2003) and Chen \& Zhu (2007) propose different ways to treat imprecise or qualitative data, focusing both on bound and ordinal data. Much of these findings are further discussed in Cook (2011), who explains that, in IDEA model, ancillary cardinal values are attributed to the imprecise data, considering the interrelation among the positions assigned to each DMU in the ordinal scale, and an additional set of restriction exclusively aimed at these qualitative variables is included in the linear program. The author adds that, for the proper modeling of IDEA, the following basic rule must be respected: for outputs, the position $\ell$ is considered favorable to the position $\ell+1$; while for inputs, $\ell+1$ is favorable to $\ell$. Such observation is necessary because a DMU tends to be more efficient as the value of its outputs grows, and as the value of the inputs decreases.

Although the importance of intangible assets for competitiveness and efficiency issues is highlighted in some research in the port sector and other industries, and albeit rather rare there are some records of the IDEA model use in the port sector, no evidence was found of its application to include intangible variables in the analyses. Nonetheless, there are studies in which the efficiency assessment is conducted in two stages, applying the DEA in the first stage, with the exclusive use of tangible variables, and other methods of analysis in later stages, identifying the functional relationships between certain contextual and environmental variables, which include intangible variables, and the tangible variables previously analyzed with DEA.

The study conducted by Zahran et al. (2017) is a rare example of the IDEA model usage for assessing port efficiency. However, the authors do not use the model to deal with qualitative inputs, but with quantitative inputs which lack precision, given the absence of factual data or the discrepancy between different sources.

\subsubsection{Model orientation}

DEA models can be either oriented to inputs or outputs. In the first case, the model is oriented towards reaching the efficient frontier by minimizing inputs, keeping outputs constant. In the second, the model seeks the maximization of outputs given a constant set of inputs (KUTIN et al., 2017).

The efficiency index of each DMU is calculated by optimizing the division between the weighted sum of inputs and the weighted sum of outputs, and for the application of the model, it is linearized. Núñez-Sánchez \& Coto-Millán (2012) point out that the choice of an input-oriented 
model is justified by the fact that the terminals usually do not have control over the annual throughput at their facilities. Still, they do control the inputs such as labor and capital.

On the other hand, Kutin et al. (2017) adopt only output-oriented models, since, according to the authors, the main concern of terminal managers is to analyze how they can increase containers throughput instead of reducing their inputs. The authors also analyze that the reduction of inputs - such as the depth of berths, the number of berths, and the size of the container yard - is not likely to occur and it represents a high cost for the terminal. Therefore, proposals in this regard are normally meaningless.

Wanke \& Barros (2016) corroborate this point of view, indicating that, although the model choice is not consensual, decision-makers, in the port context, tend to seek the maximization of outputs, considering that the inputs are supposed to be fixed in the short term. However, an output's growth potential is usually linked to the demand and must be interpreted with care since the scenario may be senseless if demand is limited (ODECK; ALKADI, 2001).

Thus, when the container throughput in TEUs is used as an output, it is necessary to consider the demand growth potential for the selected DMUs. In the Brazilian case, an indication for this is the projection exposed in the PNLP, which forecasts growth in the container demand in all regions of the country in its planning horizon (BRASIL, 2017).

\subsubsection{Target and benchmarks}

Having the DEA model and its orientation for inputs or outputs decided and the data handled, it is possible to calculate the relative efficiency for each DMU. For the inefficient ones, it is also possible to define their input or output target and its reference units (benchmarks). The envelope model's application allows the identification of benchmarks for each inefficient DMU, while its dual model, the multiplier model, enable the variables weights and the system's scale returns to be identified.

The contribution of a reference unit setting the target of each inefficient DMU is represented by a variable $\lambda$, varying from 0 to 1 , which is included in the envelope model's mathematical programming. The higher is this value, the greater is the importance of the reference for the inefficient DMU under analysis. When it is equal to 0 , it indicates that there is no relationship between both units.

\subsubsection{Comparison with other methods}

The characteristics of the DEA and the possibility provided by the method of analyzing several inputs and outputs simultaneously, in a comparative way, estimating relative efficiency indexes, make it particularly suitable for the analysis of the port sector (TONGZON, 2001). Although in general it is not necessary to develop several standards and a functional form for the data used on DEA modelling, as previously indicated, some particular issues can be incorporated into the 
analysis through alternative models, as it is the case of the IDEA model to handle intangible factors affecting the outputs.

The fact that the inputs and outputs used in the model can be expressed in different units of measure also makes the method convenient from a practical point of view and eliminates the sensitivity of the results obtained (SHEN et al., 2011). However, the successful implementation of the DEA method depends on the quality and quantity of the data collected.

In addition, there are many advantages of DEA over other methods, particularly the SFA, which reinforce the fit of its choice in this study. They are the identification of inefficiency through the comparison with similar units under analysis considered efficient; establishment of quantitative insights related to necessary adjustments for an inefficient unit to become efficient; receptivity to studies with a modest number of units analyzed; ease of interpreting the efficiency rate, which ranges from 0 to 1 ; flexibility in the selection of inputs and outputs; and the possibility of handling variables in different categories in alternative models, as is done in the case of IDEA (AVELLAR et al., 2005; BANKER; MOREY, 1986; JARBOUI et al., 2012).

One aspect that can be seen as a disadvantage of DEA compared to other methods is the limitation of the number of variables that can be used in the model. This limitation exists because the degrees of freedom in the DEA increase with the number of DMUs and decrease with the number of inputs and outputs. Cooper et al. (2007) indicate that the number of DMUs analyzed must satisfy the following condition so that the model does not incur an excessive number of units classified as efficient:

$$
n \geq \operatorname{máx}\{m \times s, 3 \times(m+s)\}
$$

where: n: number of DMUs

$\mathrm{m}$ : number of inputs

s: number of outputs

An alternative to overcome an eventual problem related to the number of units observed in situations where there is a limitation in the number of DMUs available, which is the case of this study, without neglecting relevant variables for the analysis, is the use of factor analysis and data reduction techniques. The Principal Component Analysis (ACP), as indicated by Adler \& Golany (2001), enables the reduction of variables in components that normally represent $80 \%$ to

$90 \%$ of the data variance, wherefore these components can replace the original variables without significant loss of information.

\subsection{Tangible and intangible variables}

The inputs and outputs used in efficiency analyzes can be of a qualitative or quantitative nature. Because they are more easily handled and inserted into models, quantitative variables are used more frequently than qualitative variables, with few references in the literature regarding the use of qualitative variables among DEA inputs and outputs. 
Regarding the outputs in the context of container terminals, the annual throughput, measured in TEUs, is unquestionably the most important variable and adopted most frequently (CULLINANE; WANG, 2007; LU et al., 2015). Cullinane \& Wang (2007) state that annual throughput represents the basis of a container terminal for generating revenue and the predominance of using this variable as an output of the model is evidenced in the researchers conducted by González \& Trujillo (2009) and Kutin et al. (2017).

Concerning the inputs, a significant number of different variables are used. The most frequently found inputs in the literature are listed below, noting that some of these variables partially overlap, such as the length of the berth and the number of them, and the terminal area and the yard area, so that such variables should not coexist in a model.

- Mooring length;

- Terminal area;

- Quay and yard equipment, which are considered separately or jointly, generally by quantity, and in some cases by means of indexes, with solely the quay equipment being considered in a higher frequency;

- Number of berths;

- Number of employees, considering that in some cases similar information is used to estimate this labor variable;

- Yard area, also being considered similar information in some cases, such as the capacity or number of structures, or including warehouses in those analyses that are not exclusive to container terminals.

Although not usually considered, the maximum authorized draft for berthing is also a relevant input to analyze the container terminals' efficiency. This dimension can limit the provision of services for certain shipping lines due to the vessels' dimensions or restrain them from operating at their maximum loading capacity, which are recurrent topics of discussion in the context of Brazilian port planning. This input is used in publications such as the study conducted by Mokhtar (2013), which analyzes container terminals in the Middle East, in addition to other publications that analyze Brazilian ports, such as Vieira et al. (2014) and Wanke \& Barros (2016).

Despite in real situations, it is essential to take into account the presence of qualitative data in the analysis. As pointed out by Cook \& Zhu (2006), the evaluation of efficiency in the port sector using DEA is usually based on the adoption of an exclusively quantitative data set. Nevertheless, Cho \& Kim (2015) observe that recently intangible inputs have been emphasized over tangibles with respect to competitiveness in the container terminals sector, given that tangible inputs can be imitated or also acquired by competitors, while this fact does not apply, in many cases, to the intangibles. 
Fernández et al. (2000) define intangible inputs as immaterial resources that consist of knowledge and information. The importance of such inputs in the financial results of companies is highlighted in a Bontempi \& Mairesse (2015) study that shows, for the sample analyzed, that the productivity gains related to intangible inputs are equivalent to between 1 and 4 times the gains related to tangible inputs.

Intangible variables in the port sector, as indicated by Córdova et al. (2016), improve decision making, implying the adoption of more effective and efficient strategies, and are divided into three groups: intellectual capital, organizational capital, and relationship capital. Such characteristics can be related to the managerial aspects of port authorities and serve as a basis for determining a set of intangible inputs to assess terminal efficiency.

González \& Trujillo (2009) analyze that it is possible to increase productivity in the port sector, and consequently, the production volume, at least in two different ways. The first of them is the introduction of technical progress, which can be achieved, for example, through the acquisition of a new portainer, which would also raise the efficiency frontier due to the introduction of new input.

The second way is to better use the assets of the terminal in question through the workforce's qualification, for example, enabling employees to be better prepared to handle sophisticated equipment. According to the authors, this second option would increase productivity without adding inputs, bringing the terminal closer to the efficiency frontier.

The impact caused by the addition of an intangible aspect on the productivity and the efficiency of a terminal can be clearly noted in this example. However, this example is an ad hoc analysis. If a larger number of factors involving an efficiency assessment were included, such as the simultaneous assessment of different DMUs and the consideration of several inputs and outputs, it would be difficult to relate a high or low efficiency to a factor such as the qualification of employees, unless this factor is one of the inputs being explicitly considered. In addition, it is expected that, by investing resources in training, better results will be obtained, and if this does not occur, it can be stated that this process is inefficient.

\section{MODELLING AND SOLVING THE PROBLEM}

In this study, the assessment of container terminals' relative efficiency is carried out by applying the DEA method, more specifically the IDEA model, which enables the solution of the problem in a single step and the proper handling of the intangible variable. It is adopted the output orientation since the terminals' main interest is to analyze how they can increase the containers' movement instead of reducing their inputs, as previously pointed out.

It is also assumed constant scale returns (CRS), considering that, as indicated by Tongzon (2001), the models which use VRS usually demand a higher number of DMUs to define the production frontier. It must be also noted the relative homogeneity among container terminals in developing countries, as observed by Suárez-Alemán et al. (2016), who indicate that scale efficiency one 
of the most significant determinants for the evaluation of DMU performance in regions such as Latin America and the Caribbean.

The following four subsections present: i) the definition of the assessed DMUs; ii) the chosen inputs and outputs; iii) the data collection process; iv) the treatment given to the data and the model solution.

\subsection{Decision Making Units (DMU)}

The coverage of units assessed in this study is restricted to Brazilian terminals specialized in handling containers, both terminals located in public ports and private terminals, called TUPs. Among all Brazilian terminals, the 22 representing more than $99 \%$ of the annual container throughput in Brazil in 2017 were contacted (ANTAQ, 2018).

However, it is noteworthy that nine of these terminals chose not to provide the necessary information and could not be included in the analysis. Thus, the set of DMUs considered in this study is formed by 13 Brazilian container terminals, each of them identified from now on by a letter, from A to M. For the provision of the data, it was informed that their identity would not be linked to the information. This decision was made in order to encourage managers to provide reliable data related to terminal management practices, even when they are not excellent.

\subsection{Inputs and outputs}

The variables identified as the most relevant to the context of the study, and therefore proposed for the construction of the model were:

- Tangible inputs: berth length, number of quay equipment, container yard area, and maximum authorized draft;

- Intangible input: terminal management index;

- Output: annual throughput (in TEUs).

To determine the intangible input, it was asked whether the terminals' managerial practices include a list of ten items or not. Five of those items are related to strategic management: analysis of the internal and external environments (ex: SWOT matrix); definition and control of specific objectives, indicators and targets; definition of action plans to achieve the objectives (ex: $5 \mathrm{~W} 2 \mathrm{H}$ ); guidelines for the systematic assessment of users satisfaction; and updating strategic planning at periodic intervals of less than five years. The other five items are related to operational management: the specific department responsible for planning and controlling operations; terminal operating system (TOS); periodic training program offered to the operational team; structured and formalized process flow for loading and unloading containers; and a structured and formalized plan for the maintenance of terminal equipment and infrastructure. For all of the ten items, it is given the same height. 
For the purpose of this study, it is assumed that the more items covered by a terminal, the more robust its management structure. Thus, the terminal management index of a DMU, which reports to comprise all the ten items questioned, is superior to the same input of a terminal that reports comprising eight of these items. It is not part of the scope of this study the evaluation of the quality level that each item is comprised in each terminal, and henceforth, when it is indicated that the management of a terminal is superior to another, the reference is the number of managementrelated items covered by each of them.

In line with the precepts mentioned in subsection 2.2.1 DEA models, the fact that a terminal comprises eight of the ten items listed does not mean that its management is $100 \%$ superior to the management of a terminal that comprises four of them. It is only possible to state that the former's management index is superior to the latter, as well as it is inferior to the management index of a terminal that includes all ten items.

Thus, after the data collection, the terminals were segmented into groups that include the same number of items. The value of the management variable was assigned to each terminal according to the ranking of the group in which it is located. The groups were ranked in ascending order, so that the value 1 is assumed for the terminals having more items, 2 for the group of terminals with the second largest number of items, and so on.

\subsection{Data collection}

The data collection was carried out in two distinct steps: secondary data collection and primary data collection, respecting this sequence. The collection of secondary data was carried out by consulting the Brazilian waterway statistics database, made available by ANTAQ (2018), the master plans of the port complexes where each of the analyzed terminals are inserted, and the webpages of the terminals.

With this information, surveys were sent to the terminals, filled in preliminarily to validate preliminary information and obtain the information not available in the public domain. It should be noted that the annual throughput of each terminal in 2017, measured in TEUs and obtained in ANTAQ (2018), was not validated at the terminals.

This decision was made so that the output value of each terminal respects a standard criterion since ANTAQ's database does not take into account rearrangement movements of containers in the vessel during operations, which are accounted for by terminals in most cases, thus avoiding considering such volume for some terminals and others not. It is also taken into account, for such a decision, that the data made available by ANTAQ is provided by the terminals themselves to ANTAQ, so that the reliability of the data is safeguarded.

\subsection{Data treatment and model solution}

To solve the proposed model, it was used the software Stata, since it has a package called DEAS, developed by Ji \& Lee (2010), which includes the IDEA model. In order to respect the previously 
mentioned assumption about the maximum number of variables depending on the number of units analyzed, three of the four tangible inputs were reduced into one component using the PCA method, which is also available in Stata.

The use of PCA is conditioned to the cases where there is a sufficient correlation between the variables to be reduced since the components obtained must explain the variance in the original data. Therefore, before the components were calculated, the Kaiser-Meyer-Olkin (KMO) technique was used, which, as explained by Katchova (2013), allows measuring the adequacy of the data for the application of ACP.

The KMO test results in an index that varies from 0 to 1 , calculated based on the correlation between the variables, with values greater than 0.5 being considered satisfactory. Based on the results of the KMO test, it was decided not to include the maximum authorized draft input in the reduction of variables since the index found for this input is less than 0.5 and it does not fit with the others. Therefore, the ACP was applied considering only the inputs: berth length, yard area, and quay equipment, and a component was found that represents them in a single input, designated structure.

After reducing the variables, the information collected about the each terminal's management practices was also treated, as detailed in section 3.2 Inputs and outputs, to group and rank the DMUs according to the characteristics of their management structures. At the end of this step, a total of four variables under analysis and 13 DMUs were obtained, with the necessary conditions for the model solution being met. Table 1 shows the inputs and outputs for each DMU analyzed, with which the model is run.

Table 1 - Variables used for the application of the output-oriented IDEA-CRS.

\begin{tabular}{lcccc}
\hline DMU & Inputs Structure & Draft & Management Index & Output Throughput (TEUs) \\
\hline DMU A & 3,62 & 12,70 & 1 & 811.905 \\
\hline DMU B & 4,30 & 12,80 & 1 & 743.157 \\
\hline DMU C & 2,40 & 14,50 & 3 & 618.619 \\
\hline DMU D & 2,86 & 12,80 & 1 & 592.304 \\
\hline DMU E & 2,83 & 14,40 & 1 & 460.769 \\
\hline DMU F & 3,82 & 14,00 & 1 & 351.476 \\
\hline DMU G & 1,49 & 15,00 & 2 & 301.049 \\
\hline DMU H & 3,43 & 15,70 & 1 & 282.682 \\
\hline DMU I & 6,69 & 11,00 & 1 & 270.331 \\
\hline DMU J & 1,00 & 11,00 & 1 & 251.199 \\
\hline DMU K & 2,38 & 14,90 & 1 & 209.204 \\
\hline DMU L & 2,45 & 15,00 & 1 & 74.553 \\
\hline DMU M & 2,11 & 10,80 & 4 & \\
\hline
\end{tabular}




\section{RESULTS AND ANALYSIS}

The results of the output-oriented IDEA-CRS model run are shown in Table 2. In addition to the relative efficiency of each DMU, a ranking is shown from the most efficient to the least efficient, as well as the contribution of each efficient DMU in the target formation of the inefficient DMUs $(\lambda)$.

Table 2 - Results of the output-oriented IDEA-CRS model.

\begin{tabular}{lllll}
\hline DMU & Efficiency Rate & $\begin{array}{l}\text { Benchmark } \\
\text { DMU A }(\lambda)\end{array}$ & $\begin{array}{l}\text { Benchmark } \\
\text { DMU C }(\lambda)\end{array}$ & $\begin{array}{l}\text { Benchmark } \\
\text { DMU M }(\lambda)\end{array}$ \\
\hline DMU A & 1,00 & 1 & 0 & 0 \\
\hline DMU B & 0,92 & 1 & 0 & 0 \\
\hline DMU C & 1,00 & 0 & 1 & 0 \\
\hline DMU D & 0,87 & 0,49 & 0,45 & 0 \\
\hline DMU E & 0,67 & 0,35 & 0,65 & 0 \\
\hline DMU F & 0,43 & 1 & 0 & 0 \\
\hline DMU G & 0,78 & 0 & 0,62 & 0 \\
\hline DMU H & 0,36 & 0,84 & 0,16 & 0 \\
\hline DMU I & 0,38 & 0,87 & 0 & 0 \\
\hline DMU J & 0,97 & 0 & 0,42 & 0 \\
\hline DMU K & 0,34 & 0 & 0,99 & 0 \\
\hline DMU L & 0,18 & 0,04 & 0,96 & 0 \\
\hline DMU M & 1,00 & 0 & 0 & 1 \\
\hline
\end{tabular}

It can be observed in Table 2 that three DMUs were evaluated as efficient: DMU A, DMU C, and DMU M. Regarding the other DMUs, it is possible to calculate the target value for their outputs, with which they would be considered efficient, dividing the output by the relative efficiency.

Besides that, recommendations can be made to the inefficient terminals considering the benchmarks. The inputs and outputs observed in efficient terminals with similar characteristics shall be taken as parameters to set output goals, review the inputs used and to assess operations productivity. Thus, the inefficient terminals can take the necessary measures to promote their development if they are in their sphere of action or claim them if they are not.

DMU A is the main reference for five inefficient DMUs (DMU B, DMU D, DMU F, DMU H, and DMU I), as it has the highest $\lambda$ value in relation to them. Its annual container throughput is precisely the target volume for DMU B and DMU F to achieve in order to be considered efficient, since, in these cases, $\lambda$ is equal to 1 . In the same way as DMU A, DMU C is also the main reference for five inefficient DMUs (DMU E, DMU G, DMU J, DMU K, and DMU L), especially for DMU K and DMU L, for which the value of $\lambda$ is close to 1 . Finally, although also evaluated as efficient, the DMU M does not contribute to the formation of targets of other DMUs. 
An important fact shown in the model results is that the DMU M and the DMU C, which had the two worst classifications in the management index, were evaluated as efficient. Such information tends to sound senseless since it is expected that entities in any sector that have a more robust management structure will present better results.

Nevertheless, although these DMUs have been classified as efficient, both are not among the ones that move more containers considering all the units analyzed, but just those that have the best relationship between inputs and outputs. Simulating an investment in the management structure of DMU M, which is, in fact, the one that moved fewer containers in 2017 among the 13 DMUs, ceteris paribus, its efficiency turns into the worst among all DMUs analyzed, being evaluated at a 0.14 efficiency rate.

The result of such simulation does not mean that the investment in a terminal management structure would imply a reduction in its efficiency, but that this fact should lead to an increase in the container throughput of the terminal. It should be noted that a small container terminal, for example, may not have the need of a management structure as robust as that of a larger terminal and also may not have the market and infrastructure conditions to move the same amount of containers.

Such a smaller terminal can have been idealized to serve a niche market. In this case, the fact that the management index for a small-sized terminal is worst classified than a larger terminal is not necessarily a negative aspect, and may be an indication of lean management, appropriate to its reality. It should be added that this study has not analyzed the quality of each management practice, which could be explored in further research.

\section{FINAL CONSIDERATIONS}

This study proposed a set of procedures for including intangible variables in the relative efficiency of container terminals assessment through the application of the IDEA-CRS model, in addition to the use of tangible variables that are widely disseminated in studies of this nature. The proposed intangible variable relates to the strategic and operational management practices of the terminals. As analyzed in section 4 , it contributes to understanding the current situation and the planning activities of the terminals.

The model solution resulted in three terminals considered efficient, taking into account the production frontier derived from the interrelationships between the inputs and outputs of the 13 Brazilian container terminals evaluated. Among the terminals evaluated as efficient, only one of them takes part in the group of terminals with the most robust management structure, according to the definition proposed in the study.

This finding has shown that the relationship between the terminal's management structure and its efficiency is not directly proportional. On the other hand, the inclusion of this intangible aspect in a one-step model makes more fertile the comparative analysis, encouraging the incorporation of managerial improvement needs in the same debate in which are frequently discussed container 
terminal infrastructure and superstructure improvements. These aspects can thus be considered in the priorities hierarchy.

Although adequate information has been collected for the construction, solution, and analysis of the proposed model, it should be noted that the method applied in this study is dependent on the data sent by terminals representants since such information is not disclosed to the public domain. Therefore, it is recommended that in future works, more items related to the strategic and operational management should be considered in order to increase variability in the responses regarding container terminals managerial practices, and they could be even weighted differently, using methods such as the Analytic Hierarchy Process (AHP).

Alternatively, another method for conducting data collection can be chosen. Some examples of alternative means of data collection are conducting on-site surveys or requesting the submission of corroborative documents for each information requested so that the researcher has greater control over responses. Still, the method used to determine the intangible variable values in this study can also be tested in other countries or regions that have more units to be analyzed and greater accessibility to the data, as well in other types of terminals or in other industries, in which case some adjustments shall be made.

Another recommendation for future studies involving the inclusion of management issues as one of the variables for the efficiency evaluation is the use of a data panel, to evaluate the behavior of efficiency over a set of periods. An example of this approach, with the exclusive consideration of tangible inputs, is carried out by Serebrisky et al. (2016) and Suárez-Alemán et al. (2016). With this approach, it would be possible to assess the consequences in cases where terminals have investments in infrastructure, superstructure, or management structure along the period analyzed, assuming that the return in container throughput can be observed in the short, medium, or long term. Besides, other analyses can be conducted, such as the identification of whether the terminals with the best management structure show greater efficiency growth over the years or not.

It should be also noted that, in its original mathematical formulation, DEA allows full flexibility in the variables' weights determination, therefore the model can assign higher weights to less important variables and ignore the most relevant ones. In order to solve this potential problem, some additional restrictions regarding the variable weights could be incorporated to the mathematical formulation of the multipliers model (PESSANHA et al., 2007), although Zhu (2003) states that the incorporation of the weight restrictions related to the ordinal data does not change the efficiency ratings.

Finally, the use of other intangible inputs to assess the terminals' efficiency, such as its employees' qualification, the conservation of its equipment, and the existence and quality of the road, rail, and waterway accesses, can also be considered. Although the characteristics of access to ports are variables that the terminals normally do not control, they are factors that, as indicated in Wanke \& Barros (2016) and Yeo (2010), greatly influence competitiveness and efficiency in the port sector. 


\section{References}

[1] Adler N \& Golany B. 2001. Evaluation of Deregulated Airline Networks Using Data Envelopment Analysis Combined with Principal Component Analysis with an Application to Western Europe. European Journal of Operational Research, 132(2): 260-273.

[2] Aigner D, Lovell CAK \& Schmidt P. 1977. Formulation and Estimation of Stochastic Frontier Production Function Models. Journal of Econometrics, 6(1): 21-37.

[3] ANTAQ. 2018. Anuário estatístico 2017. Accessed 18 July 2018, http://web.antaq.gov. br/Anuario2017/.

[4] Avellar JVG, Milioni AZ \& Rabello TN. 2005. Modelos DEA com variáveis limitadas ou soma constante. Pesquisa Operacional, 25(1): 135-150.

[5] Banker RD, Charnes A \& Cooper WW. 1984. Some Models for Estimating Technical and Scale Inefficiencies in Data Envelopment Analysis. Management Science, 30(9): 1031-1142.

[6] Banker RD \& Morey RC. 1986. The Use of Categorical Variables in Data Envelopment Analysis. Management Science, 32(12): 1613-1627.

[7] Barros CP. 2003. The Measurement of Efficiency of Portuguese Sea Port Authorities with DEA. International Journal of Transport Economics, 30(3): 335-354.

[8] BRASIL. 2017. Projeção de demanda e carregamento da malha PNLP 2016. Accessed 28 March 2019, http://infraestrutura.gov.br/planejamento-porturio/ 113-politica-e-planejamento-de-transportes/5424-plano-nacional-de-log.html.

[9] Bontempi ME \& Mairesse J. 2015. Intangible Capital and Productivity at the Firm Level: A Panel Data Assessment. Economics of Innovation and New Technology, 25(1-2): $22-51$.

[10] BouYssou D. 1990. Building Criteria: A Prerequisite for MCDA. In: BANA \& COSTA, C.A. (Ed.). Readings in Multiple Criteria Decision Aid. Berlin: Springer.

[11] Charnes A, Copper WW \& Rhodes E. 1978. Measuring the Efficiency of Decision Making Units. European Journal of Operational Research, 2(6): 429-444.

[12] Chen Y \& ZHU J. 2007. Interval and Ordinal Data: How Standard Linear DEA Model Treats Imprecise Data. In: ZHU, J.; COOK, W. D. (Eds.). Modeling Data Irregularities and Structural Complexities in Data Envelopment Analysis. Boston: Springer.

[13] Cho H \& Kim S. 2015. Examining Container Port Resources and Environments to Enhance Competitiveness: A Cross-Country Study from Resource-Based and Institutional Perspectives. The Asian Journal of Shipping and Logistics, 31(3): 341-362. 
[14] Cook WD. 2011. Qualitative Data in DEA. In: COOPER, W. W.; SEIFORD, L. M.; ZHU, J. (Eds.). Handbook on Data Envelopment Analysis. 2 ed. Boston: Springer.

[15] Cook WD \& ZHU J. 2006. Rank Order Data in DEA: A General Framework. European Journal of Operational Research, 174(2): 1021-1038.

[16] CoOper WW, PARk KS \& Yu G. 1999. IDEA and AR-IDEA: Models for Dealing with Imprecise Data in DEA. Management Science, 45(4): 455-620.

[17] Córdova FM, Durán CA \& Galindo R. 2016. Evaluation of Intangible Assets and Best Practices in a Medium-sized Port Community. Procedia Computer Science, 91: 75-84.

[18] Cullinane K \& Wang T. 2010. The Ef[FB01?]ciency Analysis of Container Port Production Using DEA Panel Data Approaches. OR Spectrum, 32(3): 717-738.

[19] Cullinane K \& Wang T. 2007. The Efficiency of European Container Ports: A Crosssectional Data Envelopment Analysis. International Journal of Logistics Research and Applications, 9(1): 19-31.

[20] Farrell MJ. 1957. The Measurement of Productive Efficiency. Journal of the Royal Statistical Society, 120(3): 253-290.

[21] Fernández E, Montes JM \& VÁzquez CJ. 2000. Typology and Strategic Analysis of Intangible Resources: A Resource-Based Approach. Technovation, 20(2): 81-92.

[22] GonzÁlez MM \& Trujillo L. 2009. Efficiency Measurement in the Port Industry: A Survey of the Empirical Evidence. Journal of Transport Economics and Policy, 43(2): 157-192.

[23] Jarboui S, Forget P \& Boujelbene Y. 2012. Public Road Transport Efficiency: A Literature Review via the Classification Scheme. Public Transport, 4(2): 101-128.

[24] Ji Y \& LEE C. 2010. Data Envelopment Analysis. Stata Journal, 10(2): 267-280.

[25] Katchova A. 2013. Econometrics Models: Principal Component Analysis. Econometrics Academy. Accessed 29 January 2019, https://sites.google.com/site/ econometricsacademy/econometrics-models/principal-component-analysis.

[26] Kutin N, Nguyen TT \& Vallée T. 2017. Relative Efficiencies of ASEAN Container Ports Based on Data Envelopment Analysis. The Asian Journal of Shipping and Logistics, 33(2): 67-77.

[27] Lloyd's List. 2017. One Hundred Ports 2017. Accessed 27 February 2018, https:// lloydslist.maritimeintelligence.informa.com/one-hundred-container-ports- 2017.

[28] Mokhtar K. 2013. Technical Efficiency of Container Terminal Operations: a DEA Approach. Journal of Operations and Supply Chain Management, 6(2): 1-19. 
[29] Notтeвоом T. 2012. Container Shipping. In: TALLEY, W. K. (Ed.). The Blackwell Companion to Maritime Economics. Oxford, UK: Wiley-Blackwell.

[30] NúÑez-SÁnchez REP \& Coto-Millán P. 2012. The Impact of Public Reforms on The Productivity of Spanish Ports: A Parametric Distance Function Approach. Transport Policy, 24: 99-108.

[31] Odeck J \& AlKadi A. 2001. Evaluating Efficiency in the Norwegian Bus Industry Using Data Envelopment Analysis. Transportation, 28(3): 211-232.

[32] PAK JY, Thai VV \& Yeo GT. 2015. Fuzzy MCDM Approach for Evaluating Intangible Resources Affecting Port Service Quality. The Asian Journal of Shipping and Logistics, 31(4): 459-468.

[33] Pessanha JFM, Souza RC \& Laurencel LC. 2007. Um modelo de análise envoltória de dados para o estabelecimento de metas de continuidade do fornecimento de energia elétrica. Pesquisa Operacional, 27(1): 51-83.

[34] Serebrisky T, Sarriera JM, Suárez-Alemán A, Araya G, BriceñoGarmendía C \& SCHWARTZ J. 2016. Exploring the Drivers of Port Efficiency in Latin America and the Caribbean. Transport Policy, 45: 31-45.

[35] Shen Y, Ruan D, Hermans E, Brijs T, Wets G \& Vanhoff K. 2011. Modeling Qualitative Data in Data Envelopment Analysis for Composite Indicators. International Journal of System Assurance Engineering and Management, 2(1): 21-30.

[36] Souza GS, Gomes EG, Magalhães MC \& Ávila, AFD. 2007. Economic efficiency of Embrapa's research centers and the influence of contextual variables. Pesquisa Operacional, 27(1): 15-26.

[37] SuÁrez-Alemán A, SArriera JM, Serebrisky T \& Trujillo L. 2016. When It Comes to Container Port Efficiency, Are All Developing Regions Equal? Transportation Research Part A: Policy and Practice, 86: 56-77.

[38] Tongzon J. 2001 Efficiency Measurement of Selected Australian and Other International Ports Using Data Envelopment Analysis. Transportation Research Part A: Policy and Practice, 35(2): 107-122.

[39] UNCTAD. 2018. Handbook of Statistics 2017. Accessed: 27 February 2018, http: //unctad.org/en/PublicationsLibrary/tdstat42\_en.pdf.

[40] Vieira GBB, Gonçalves RB, Milan GS \& Rosa AQ. 2014. Avaliação da Eficiência Portuária Utilizando a Análise Envoltória de Dados: Um Estudo dos Terminais de Contêineres dos Portos da Região Sul do Brasil. Revista Gestão Industrial, 10(4): 793-809. 
[41] Wanke PF \& Barros CP. 2016. New Evidence on the Determinants of Efficiency at Brazilian Ports: A Bootstrapped DEA Analysis. International Journal of Shipping and Transport Logistics, 8(3): 250-272.

[42] Yeo H. 2010. Competitiveness of Asian Container Terminals. The Asian Journal of Shipping and Logistics, 26(2): 225-246.

[43] Zahran SZ, Alam JB, Al-Zahrani AH, Smirlis Y, Papadimirtriou S \& Tsioumas V. 2017. Analysis of Port Efficiency Using Imprecise and Incomplete Data. Operational Research, 20: 1-28.

[44] ZHU J. 2003. Efficiency evaluation with strong ordinal input and output measures. European Journal of Operational Research, 146(3): 477-485.

\section{How to cite}

Alves CF \& Seabra F. 2021. An application of the idea model in the assessment of container terminals efficiency with an intangible input. Pesquisa Operacional, 41: e244934. doi: 10.1590/0101-7438.2021.041.00244934. 